\title{
Influence of halloysite nanotubes on physical and mechanical properties of cellulose fibres reinforced vinyl-ester composites
}

\author{
A.M. Alhuthali and I.M. Low \\ Department of Imaging \& Applied Physics, Curtin University, GPO Box U1987, Perth, WA \\ 6845, Australia \\ *Corresponding author - Email: j.low@curtin.edu.au; Tel: +61-8-9266 7544; \\ Fax: +61-8-9266 2377
}

\begin{abstract}
Natural fibres are generally added to polymer matrix composites to produce materials with the desirable mechanical properties of higher specific strength and higher specific modulus while at the same time to maintain a low density and low cost. The physical and mechanical properties of polymer composites can be enhanced through the addition of nano-fillers such as halloysite nanotubes (HNTs). This paper describes the fabrication of vinyl ester ecocomposites and eco-nanocomposites and characterises these samples in terms of water absorption, mechanical, and thermal properties. Weight gain test and FTIR analysis indicated that $5 \% \mathrm{HNT}$ addition gave favourable reduction in the water absorption and increased the fibre-matrix adhesion leading to improved strength properties in the eco-nanocomposites. However, HNT addition resulted in reduced toughness but improved thermal stability.
\end{abstract}

\section{Keywords}

Vinyl ester (VER), halloysite nanotubes (HNTs), recycled cellulose fibre (RCF), water uptake, mechanical properties, thermal properties 


\section{Introduction}

Halloysite nanotubes (HNTs) are derived from naturally deposited alumino-silicate $\left(\mathrm{Al}_{2} \mathrm{Si}_{2} \mathrm{O}_{5}\right.$ $\left.(\mathrm{OH})_{4} \cdot \mathrm{H}_{2} \mathrm{O}\right)$ and are chemically similar to kaolin. ${ }^{1}$ Structurally, due to mismatch between tetrahedral and octahedral internal components, HNTs take on a cylindrical shape forming the tubes which are typically between 1 and $15 \mu \mathrm{m}$ in length. ${ }^{2}$ These tubes have dimensions of between 50 and $70 \mathrm{~nm}$ for the outer diameters and between 10 and 30 for the $\mathrm{nm}$ inner diameters. As the tubes are hollow, they allow HNTs to have very high surface area with a high aspect which promotes excellent interaction between the filler and matrix. ${ }^{3}$ Tensile, fracture and impact strength as well as other mechanical and thermal properties are believed to be dramatically improved when HNTs are added to epoxy, polystyrene, polypropylene, polyvinyl-alcohol, and other polymers. ${ }^{4}$

Natural fibres are eco-friendly, commercially-viable fillers, that have excellent modulus to weight ratios and are capable of forming polymer composites with excellent toughness properties. ${ }^{5}$ Natural fibres are biodegradable unlike some plastics, and have a production which energy-efficient and often less expensive that, production with synthetic counterparts. ${ }^{6,7}$ Natural fibres are lighter than synthetic materials, and having an excellent modulus to weight ratio, are ideal for stiffness-critical designs needed in construction, automotive, and even aerospace industries. ${ }^{7}$ Acoustic damping properties of natural fibres make them suitable for use in components in the internal areas of automobiles. ${ }^{8}$ Compared to synthetic fibres, many natural fibers have elastic modulus and specific modulus comparable or better than synthetic fiber composites. ${ }^{7,8}$

Vinyl ester resins are a newer thermosetting resin compared to alternatives such as polyester and epoxy resins. In terms of industrial applications, the desirable properties of vinyl-ester resins make them suitable for adhesives, coatings, electrical applications, moulding 
compounds and structural laminates. Thus, vinyl-ester resins that combine the most soughtafter properties of epoxies and unsaturated polyesters are favoured by the industry ${ }^{9}$.

So far studies have established that the addition of natural fibres to polymer matrices as a micro-scale reinforcement material provides toughness and strength to these composites. ${ }^{10}$ Barrier, thermal, and mechanical properties of polymeric composites can also be improved by adding a low concentration of nano-filler particles as a nano-scale reinforcement material. ${ }^{11}$ The combination of multi-scale reinforcement materials in polymer matrix can provide the reinforcements properties at two scales. However, incorporation nano-fillers to natural fibre polymer composites, is an area that has not been widely investigated.

The selection of HNTs as the nano-filler to be incorporated in natural fibre polymer composites for the purposes of development and characterisation is a novel proposition and one which it seems has yet to be attempted by the scientific community at this time. This study, therefore, aimed to investigate this addition of HNTs to vinyl-ester reinforced with recycled cellulose fibre and to characterise the resulting composite's properties in terms of water absorption, mechanical, thermal, and flammability. A novel finding on the functions of HNT particles was revealed by the water uptake behaviours and fibres-matrix adhesion.

\section{Experimental}

\section{Materials}

Recycled cellulose fibre in sheets form (RCF), grade 80GSM, $100 \mu \mathrm{m}$ thickness, supplied by Todae Company, NSW, Australia; a general purpose vinyl ester resin, supplied by Fibreglass \& Aesin Sales Pty Ltd, WA, Perth, Australia, and ultrafine halloysite nanotubes (HNTs) with $50.4 \% \mathrm{SiO}_{2}, 35.5 \% ; \mathrm{Al}_{2} \mathrm{O}_{3}, 0.25 ; \mathrm{Fe}_{2} \mathrm{O}_{3}$, and $0.05 ; \mathrm{TiO}_{2}$ (wt $\%$ ), supplied by $\mathrm{NZCC}$, New Zealand, were used in this study. 


\section{Preparation of Samples}

Preparation of pure samples. Vinyl ester samples (VER) were first made as a control to provide the baseline data of the properties of pure vinyl ester resin. The vinyl ester resin was mixed with $1.0 \mathrm{wt} \%$ methyl ethyl ketone peroxide (MEKP) in order to prepare the samples. The mixture was slowly and thoroughly mixed to ensure that no air bubbles formed within the matrix. The resultant mixture was poured into silicon moulds and left under low vacuum (20 kPa) for two hours and later left at room temperature for 24 hours to cure.

Preparation of eco-composites. Recycled cellulose-fibre sheets (RCF) were dried for 60 minutes at $150^{\circ} \mathrm{C}$. RCF sheets were then fully soaked in the vinyl-ester system. Next, the sheets were laid up in a silicon mould under compressive pressure (10.2 kPa) and then placed under vacuum $(60 \mathrm{kPa})$ for two hours. Then samples left to cure for 24 hours at room temperature. The weight percentage of fibres in these eco-composites was $40 \%$.

Preparation of eco-nanocomposites. Nanocomposites containing different concentrations, namely, 1, 3, and 5 wt $\%$ HNTs were prepared. HNTs was first dried for 60 minutes at $150^{\circ} \mathrm{C}$, and then mixed with vinyl ester resin for 30 min using high speed electrical-mixer. The mixtures were then left under vacuum of $(60 \mathrm{kPa})$ to remove air bubbles. After that, catalyst was added and mixed manually to avoid creating air-bubbles inside the composites. Next, the mixtures were then reinforced with the same percentage of RCF sheets $(40 \mathrm{wt} . \%)$. The sheets were also dried for 60 minutes at $150^{\circ} \mathrm{C}$. The sheets were then fully soaked in the mixtures and pressed together under $20 \mathrm{~kg}$ and under vacuum of (60 $\mathrm{kPa}$ ) for two hours. Finally, the samples were left to cure at room temperature for 24 hours. The resultant eco-nanocomposites were labelled as VER/RCF/1\%HNTs, VER/RCF/3\%HNTs and $\mathrm{VER} / \mathrm{RCF} / 5 \% \mathrm{HNTs}$, respectively 


\section{Characterization}

\section{Microstructure examination}

Samples were measured on a D8 Advance Diffractometer (Bruker-AXS) using copper radiation and a LynxEye position sensitive detector. The diffract meter were scanned from $3^{\circ}$ to $50^{\circ}(2 \theta)$ in steps of $0.02^{\circ}$ using a scanning rate of $0.5^{\circ} / \mathrm{min}$ XRD patterns obtained by using $\mathrm{Cu} \mathrm{K} \alpha$ lines $(\lambda=1.5406 \AA)$. A knife edge collimator was fitted to reduce air scatter.

To study the morphologies of the HNTs and their dispersion inside the vinyl-ester matrix, a transmission electron microscope (JEOL JEM2011, Japan) was used. A NEON 40ESB, scanning electron microscope, SEM, (ZEISS, UK) operating at accelerating voltage of $5 \mathrm{kV}$, under secondary electrons mode was used to examine the microstructure of HNTs and fracture surfaces of the samples. In order to avoid charging, all samples were coated with platinum.

\section{Water uptake properties}

Samples with rectangular-shaped dimensions $(10 \mathrm{~mm} \times 10 \mathrm{~mm} \times 6 \mathrm{~mm})$ were used. Individual samples were soaked in tap water at room temperature. At prescribed intervals, samples were removed from water. After excess water was removed, they were weighed and immediately returned to the water. The amount of moisture uptake or absorbed $\left(M_{A}\right)$ by the samples over a period of 120 days, was determined using the following equation: ${ }^{9}$

$$
M_{A}=\frac{M_{T}-M_{D}}{M_{D}} \times 100
$$

where $M_{D}$ is the dry mass and $M_{T}$ is the mass of sample soaked for time $t$.

Diffusion coefficient of samples have been calculated by using the following equation: ${ }^{12}$

$$
D=\frac{\pi}{16}\left(\frac{M_{t} / M_{\infty}}{\sqrt{t / h}}\right)^{2}
$$


where $M_{\infty}$ is maximum water uptake, $M_{t}$ is water uptake at time $t, h$ is sample thickness, and $D$ is diffusion coefficient.

Fourier transform infrared analysis

A Perkin Elmer Spectrum 100 FTIR (Perkin Elmer, USA) infrared spectrometer was used for the Fourier transform spectroscopy analysis (FTIR). The spectral resolution was 4 wavenumbers. The FTIR analysis was conducted to determine the water content of the samples after the water absorption experiment. An ATR correction was performed to compensate for the wavelength dependence on penetration depth. Thin slice samples with dimensions $5 \mathrm{~mm} \times 5 \mathrm{~mm} \times 1 \mathrm{~mm}$ for both the dry- and wet-condition specimens were prepared. The dry condition samples were dried for 15 minutes at $100^{\circ} \mathrm{C}$ prior to FTIR analysis to remove existing moisture. The wet-condition samples were immersed in water for 120 days, and immediately prior to FTIR analysis, these samples were left at room temperature $\left(\sim 25^{\circ} \mathrm{C}\right)$ for 5 minutes to remove surface moisture.

\section{Flexural strength}

Rectangular bars of $60 \mathrm{~mm} \times 10 \mathrm{~mm} \times 6 \mathrm{~mm}$ were cut from the fully-cured samples for three-point bend tests with a span of $40 \mathrm{~mm}$ to evaluate the flexural strength. A LLOYD Material Testing Machine $(5-50 \mathrm{kN})$ with a displacement rate of $1.0 \mathrm{~mm} / \mathrm{min}$ was used to perform the test. Five samples of each batch were used to evaluate flexural strength. The values of were recorded and analyzed with the machine software (NEXYGENPlus) and average values were calculated. 


\section{Impact strength}

To determine impact strength $\sigma_{i}$, a Zwick Charpy impact tester with a $2.0 \mathrm{~J}$ pendulum hammer was used. Five 40mm-span bar samples in edgewise position were assessed. Impact strength was calculated using the following equation: ${ }^{13}$

$$
\sigma_{i}=\frac{E}{A}
$$

where $E$ is the impact energy to break a sample with a ligament of area $A$.

\section{Fracture toughness}

For the fracture toughness $\left(K_{I C}\right)$ measurement, the ratio of notch length to width of sample $(a / w)$ used was 0.4 and a sharp razor blade was used to initiate a sharp crack. The flexural tests were performed with a LLOYD Material Testing Machine using a displacement rate of $1.0 \mathrm{~mm} / \mathrm{min}$; five samples of each composition were used for the measurements. The value of $\left(K_{I C}\right)$ was computed using the following equation: ${ }^{14}$

$$
K_{I C}=\frac{p_{m} S}{W D^{2 / 3}} f\left(\frac{a}{w}\right)
$$

where $p_{m}$ is the maximum load, $S$ is the span of the sample, $D$ is the specimen thickness, $w$ is the specimen width, and $a$ is the crack length, and $f(a / w)$ is the polynomial geometrical correction factor given as: ${ }^{14}$

$$
f(a / w)=\frac{3(a / w)^{1 / 2}\left[1.99-(a / w)(1-a / w)\left(2.15-3.93 a / w+2.7 a^{2} / w^{2}\right)\right]}{2(1+2 a / w)(1-a / w)^{2 / 3}}
$$




\section{Impact toughness}

To determine the impact toughness $\left(G_{I C}\right)$, a Zwick Charpy-impact tester with a $2.0 \mathrm{~J}$ pendulum hammer was used. Five 40mm-span bar samples in edgewise position with varying notch lengths and razor-sharp cracks were used. The value of impact toughness was calculated using the equation: ${ }^{14}$

$$
U=G_{I C} B D \phi+U_{0}
$$

where $U$ is the measured energy, $U_{0}$ is the kinetic energy, $D$ is the specimen thickness, $B$ is the specimen breadth, and $\phi$ is the calibration factor for the geometry used.

\section{Thermal and flammability test}

A differential thermo-gravimetric analyser (TGA-DTA; Instrument: 2960 SDT V3.0F) was used to examine thermal behaviours of composites. At a rate of $20^{\circ} \mathrm{C} / \mathrm{min}$, composites were heated from room temperature to $800^{\circ} \mathrm{C}$. Thermal decomposition temperatures of the composites were examined under $20 \mathrm{ml} / \mathrm{min}$ of nitrogen using platinum pans. Horizontal burning testing determined flammability in terms of ignition time, burning-out time and fire velocity. For each composite, three samples $(100 \mathrm{~mm} \times 10 \mathrm{~mm} \times 10 \mathrm{~mm})$ were prepared and hung on a retort stand and a constant flame source was applied.

\section{Results and discussions}

\section{$X$-ray diffraction analysis $(X R D)$}

XRD patterns for pure HNTs and VER/RCF/HNTs composites with $1 \%, 3 \%$ and $5 \mathrm{wt} \%$ of HNTs are shown in Figure 1. A diffraction peak at $2 \theta$ at around $12.27^{\circ}$ related to the $(001)$ plane can be seen in XRD pattern of pure HNTs. A highly-disordered tubular morphology featuring inter-stratification of layers with various hydration states and small crystal size is 
indicated by this basal reflection. ${ }^{15}$ Two additional diffraction peaks at $2 \theta \approx 20.15^{\circ}$ and $2 \theta \approx$ $24.95^{\circ}$ which relate to the $(020)$ and $(002)$ basal reflections are noticeable. ${ }^{1,22}$ Trace amounts of quartz and feldspar in powders are also evident and are represented by (*) and (+) respectively. The presence of these minerals in HNT samples has been noted by other researchers. ${ }^{15,16}$ For pure HNT samples, a diffraction peak at $2 \theta=12.27^{\circ}$ corresponds to a basal spacing of $0.721 \mathrm{~nm}$. For VER/HNT composites, the diffraction peak has shifted towards lower $2 \theta$ values. The diffraction peaks, with the corresponding basal spacing shown in parenthesis, for VER/1\%HNTs, VER/3\%HNTs, and VER/5\%HNTs were $11.87^{\circ}(0.745$ $\mathrm{nm}), 12.07^{\circ}(0.733 \mathrm{~nm})$, and $12.15^{\circ}(0.728 \mathrm{~nm})$ respectively (Table 1$)$. The evidence of intercalation between VER chains and the HNTs is strongly supported by the $2 \theta$ reductions or the increases in the basal spacing of the HNTs in these composites, which further confirms the formation of nano-composites as found in other studies. ${ }^{1,4}$ In relation to the two additional diffraction peaks displayed in the XRD pattern for pure HNTs, the subsequent XRD patterns for the composites samples revealed that the pure HNTs peak at $2 \theta$ at around $20.15^{\circ}$, for the composites, had shifted markedly lower, and the pure HNTs peak at $2 \theta$ at around $24.95^{\circ}$, for the composites, had almost completely vanished. These results support the existence of intercalation of the VER chain into the structure of the HNTs.

\section{Microstructure of HNTs and VER/RCF/HNT composites}

The SEM and TEM images of HNTs reveal that the majority of HNTs exist in a tubular shape and this is evidenced in Figure 2. The presence of short tubular HNTs, semi-rolled HNTs, and pseudo-spherical HNTs is evident. A mean particle size of $2 \mu \mathrm{m}$ and a length of HNTs ranging from $400 \mathrm{~nm}$ to $3 \mu \mathrm{m}$ were determined. The aspect ratio of HNTs varies between 1.5, 3 and 10. The inner diameters range from 50-150 nm while the outer diameters of the HNTs range from 150-500 $\mathrm{nm}$. The TEM micrographs (Figure 3) show that there is an 
acceptable degree of dispersion of HNT particles or clusters within the composites for 1,3 and $5 \mathrm{wt} \%$ HNTs.

\section{Water uptake properties}

\section{Weight gain test}

Water absorption curves of the eco-composites and eco-nanocomposites are shown in Figure 4. When the samples were first exposed to water, the process of water absorption occurred rapidly then gradually the absorption rate slowed down until equilibrium, these behaviours follow the Fickian diffusion behaviour. ${ }^{12}$ Clearly, increasing the HNT addition to the system has resulted in a reduction in the uptake of water. The most plausible explanation for this is that HNTs interfere with the transfer paths of water molecule by transforming the original path of direct-fast diffusion into a torturous or maze-like path which slows water absorption and reduces the overall uptake of water. The impermeability of nanocomposites provided by HNTs prevents their complete saturation and causes maximum water uptake to be lower. ${ }^{17,18}$ The maximum water uptake $M_{\infty}$ and diffusion coefficient $D$ values for all composites are shown in Table 2. The amount of water absorbed decreased as the HNT loading increased, thus indicating the desirable effect of HNTs in reducing water absorption in the composites.

\section{FTIR analysis}

The FTIR spectra of eco-composites and eco-nanocomposites in dry- and wet-conditions are shown in Figure 5 (a-b). A broad peak representing the stretching of hydroxyl groups between 3000 and $3700 \mathrm{~cm}^{-1}$ can be seen for each spectrum in dry conditions due to $\mathrm{OH}$ ions present in VER, RCF and HNTs. ${ }^{19-21}$ This broad peak will be reference for the description of water absorption behavior.

Additional peaks also caused by presence of VER, RCF and HNTs can be seen in addition to this broad peak. A strong peak at $\sim 2924 \mathrm{~cm}^{-1}$ and weaker peak at around $2870 \mathrm{~cm}^{-1}$ caused by 
the presence of VER and RCF can be seen in all spectra displayed. It is expected that these peaks are due to symmetric and asymmetric vibration from $\mathrm{CH}^{22}$ The absorption peak at 830 $\mathrm{cm}^{-1}$ is believed to be caused by bending vibrations of the vinylic group in vinyl ester whereas the peak near $947 \mathrm{~cm}^{-1}$ is believed to be caused by out-of-plane bending of vinyl ester monomer. ${ }^{23}$ The bending vibration peak at $\sim 1450 \mathrm{~cm}^{-1}$ for methyl groups, and $1350 \mathrm{~cm}^{-1}$ and $1380 \mathrm{~cm}^{-1}$ for methylene groups are due to symmetric and asymmetric vibration from $\mathrm{CH} \cdot{ }^{24}$ Absorption peaks seen at $1607 \mathrm{~cm}^{-1}$ and $1510 \mathrm{~cm}^{-1}$ are attributed to the benzene ring of vinyl-ester while peaks at $\sim 1720 \mathrm{~cm}^{-1}$ and $1180 \mathrm{~cm}^{-1}$ are due to the carbonyl groups of the ester linkage. ${ }^{25}$ The presence of HNTs is believed to cause at least three more peaks. The peak at around $1030 \mathrm{~cm}^{-1}$ is caused by perpendicular $\mathrm{Si}-\mathrm{O}$ stretching whereas the peak at $1113 \mathrm{~cm}^{-1}$ is caused by apical $\mathrm{Si}-\mathrm{O}$ vibration. The stretching of the Al-O/Al-OH bonds is responsible for the peak at $\sim 912 \mathrm{~cm}^{-1} .^{23}$

The water absorption of composites for 120 days caused an increase in the broad peak of hydroxyl stretching. The higher frequency region of the peak is due to hydroxyl stretching which is caused by the hydroxyl peak of absorbed liquid water. The effects of absorbed liquid water are considered to include the effects of un-associated water, loosely bound water, as well as the indirectly bonded water which may be bonded to the hydroxyl groups using other water molecules. The lower frequency region of the peak is a result of hydroxyl stretching caused by hydroxyl stretching of strongly bound water. Strongly bound water is produced when direct hydrogen bonds are formed between the hydroxyl groups of absorbed water and the composite components. ${ }^{26}$

The broad peaks, centred at around $3340 \mathrm{~cm}^{-1}$, are shown in Figure 6. These peaks increased after 120 days of immersion in water. The respective FTIR spectra reveal that there were differing quantities of moisture absorbed for each composite. The addition of HNTs was found to lead to a decrease in water uptake behaviours. This provides further support for the premise that HNT addition increases the resistance to water absorption. When compared to 1 
and $3 \mathrm{wt} \%$ HNTs, the addition of $5 \mathrm{wt} \%$ HNTs led to the greatest resistance to water absorption as evidenced by the studies on weight gain and FTIR.

\section{Elastic modulus and strength properties}

Table 3 displays the results for elastic modulus, flexural strength and impact strength. Compared to pure VER, eco-composites and eco-nanocomposites had greater elastic modulus. In particular, the elastic modulus of eco-composites VER/RCF increased by 162.3 $\%$. The improvement in elastic modulus is due to the higher initial modulus of the cellulose fibres acting as backbones in the composites. ${ }^{27}$

The flexural strength of eco-composite (148.4 MPa) was more than three times that of the pure sample (41.9 MPa). These significant enhancements in strength properties are attributed to the reinforcing effect imparted by cellulose fibers which are of high strength and modulus. Moreover, the ability of cellulose fibres in resisting bending force is also a contributor in the improved flexural strength. ${ }^{28}$ Since the role of matrix is to transfer the load to the stiff fibers through shear stresses at the interface, a good bond between the polymeric matrix and the fibers is required in this process. ${ }^{29}$

When compared to pure VER, the impact strength of eco-composites was found to be six times larger at $15.9 \mathrm{~kJ} / \mathrm{m}^{2}$. As impact strength is defined as the ability of a material to resist fracture under conditions of stress applied at high speed, the marked enhancement of impact strength in the eco-composites can be attributed to cellulose fibres having a superior ability to absorb impact energy compared to pure polymer. ${ }^{30}$ Similarly, good interfacial bonding is required for composites to exhibit enhanced impact strength. This is because when there is good bonding between fibres and matrix, the load requires for de-bonding or fibre pull-outs will be high and thus high impact resistance can be expected. ${ }^{31}$ Previous studies have documented these improvements in elastic modulus and strength properties in polymer composites reinforced with natural fibers. ${ }^{30,32}$ 
The addition of HNTs to VER/RCF composites resulted in eco-nanocomposites with increased elastic modulus. Compared to unfilled eco-composites, eco-nanocomposites reinforced with 1, 3 and 5 wt $\%$ of HNTs exhibited enhanced elastic moduli of 5.1, 5.8 and 5.2 GPa respectively. Halloysite nanotubes have a high specific surface area which is favourable for interfacial interaction with the polymer matrix, thus promoting stronger bonding at the interfaces. Hence, HNTs are expected to hinder the mobility of surrounding chains in the polymer matrix, thus increasing the matrix stiffness. ${ }^{9,33}$ Moreover, HNTs have a higher elastic modulus (i.e. 10.1 GPa) when compared to pure VER $(2.97 \mathrm{GPa})$ or VER/RCF ecocomposites (4.8 GPa).

The addition of HNTs imparted a moderate increase in both flexural strength and impact strength. When eco-composites were reinforced with 1,3 and $5 \mathrm{wt} \%$ HNTs, the flexural strength of eco-nanocomposites increased from 148.4 MPa to 156.1, 161.2 and 150.2 $\mathrm{MPa}$ respectively. Similarly, the addition of HNTs at 1, 3, and $5 \mathrm{wt} \%$ increased the impact strength from $15.9 \mathrm{~kJ} / \mathrm{m}^{2}$ to $16.8,18.9$ and $16.1 \mathrm{~kJ} / \mathrm{m}^{2}$ respectively.

The SEM micrographs in Figure 7 show the fracture surfaces of all samples. The investigation of the quality of fibre-matrix adhesion is based on fibre pull-outs, disparity in fibre lengths, fibre surfaces, and fibre-matrix gaps. Figure 7a shows that the pull-out lengths, the extent that individual fibres are debonded, were greater in the eco-composites when compared to eco-nanocomposites shown in Figures 7b, c and d. Moreover, Figure 7a shows that the number of fibres that were pulled out was greater in the eco-composites when compared to eco-nanocomposites. Th greater pull-out lengths and greater number of fibres pulled-out in eco-composites is a consequence of poor interfacial adhesion and can be contrasted with the stronger fibres-matrix adhesion in eco-nanocomposites. ${ }^{31,34}$ In the case of weak fibre-matrix adhesion, cracks propagate along the debonded fibre-matrix interfaces and result in greater fibre pull-out length and number. In contrast, when fibre-matrix adhesion is 
strong, the propagation of cracks along the debonded interfaces is less and thus less fibre pull-outs.

Interestingly, with loading of HNTs the length and number of fibres pulled out was clearly reduced compared to eco-composites. In eco-nanocomposites with $3 \mathrm{wt} \%$ HNTs almost no fibre pull-outs are observed and the fibres can be seen to be fractured instead due to strong interfacial bonding. Another distinguishing feature of the eco-composites is the clean appearance of the fibre surfaces. This clean appearance is another indicator of poor adhesion between the matrix and fibres. This contrasts with the rough appearance of fibre surfaces in eco-nanocomposites as a result of strong fibre-matrix adhesion. ${ }^{35}$ Finally, the matrix-fibre gaps appear larger in the eco-composites compared to the eco-nanocomposites. These observations indicate that the addition of HNTs leads to stronger adhesion between fibrematrix with concomitant strength improvements. The high surface area of HNTs increases the contact area within the matrix and thereby increases the interfacial bonding between the fibre and the polymer matrix. ${ }^{36,37}$ In addition; HNTs can provide strong attractive forces to further enhance adhesion between the fibres and the matrix. ${ }^{38}$

With regards to the addition of $5 \mathrm{wt} \%$ HNTs, it was found that this concentration led to less improvement in strengths when compared 1 and $3 \mathrm{wt} \%$ HNTs. Processing events are believed to underpin the failure of $5 \mathrm{wt} \%$ HNTs addition to further improve the strength. When there is a high loading of HNTs, the viscosity increases during mixing of resin and HNTs rendering insufficient degassing before curing. It is vital that during processing a complete degassing process is ensured for the composite to minimize void formation. The formation of voids in composites can act as stress-concentrators to reduce the strength. ${ }^{39}$ The SEM images in Figure 8 compares the fracture surfaces due to void formation in sample with $5 \mathrm{wt} \%$ HNTs with void-free samples with 1 and 3 wt $\%$ HNTs. 
The ASTM D2734-94 standard ${ }^{40}$ was used to determine void content or porosity of the composite samples. The void contents for eco-composites and 1, 3, and 5 wt $\%$ econanocomposites were determined to be $3.3 \%$ and $1.1,0.57$ and $3.1 \%$ respectively. Econanocomposites exhibited a lower void content when compared to eco-composites. Econanocomposites with $3 \mathrm{wt} \%$ exhibited the lowest void content $(0.57 \%)$. However, the void content for $5 \mathrm{wt} \%(3.1 \%)$ was almost the same as the unfilled eco-composites $(3.3 \%)$. A plausible explanation is that the addition of $5 \mathrm{wt} \%$ HNTs caused an increase in the resin viscosity, thus resulting in a reduction of fibre wettability by the matrix or interfacial adhesion.

SEM observations of fibre/matrix adhesion combined with the calculation values of void content support the observed strength results. Thus, the higher strengths exhibited by $3 \mathrm{wt} \%$ eco-nanocomposites are attributed to strong fibre/matrix adhesion and low void content. In contrast, weaker fibre/matrix adhesion and higher void contents resulted in lower strength.

\section{Toughness properties}

Table 4 shows that, compared to pure samples, the eco-composites have greater fracture toughness and impact toughness. The improved fracture toughness may be attributed to the pronounced display of crack-deflection, interfacial de-bonding, fibre-bridging and pull-outs in these materials. ${ }^{29,31}$ When compared to pure VER samples which are quite brittle like all thermosetting resins ${ }^{9}\left(1.8 \mathrm{MPa}^{1 / 2}\right)$, eco-composites are much tougher with $4.4 \mathrm{MPa} \cdot \mathrm{m}^{1 / 2}$. Similarly, compared to pure samples, with an impact toughness of $1.5 \mathrm{~kJ} / \mathrm{m}^{2}$, eco-composites are also much tougher with an impact toughness of $42.3 \mathrm{~kJ} / \mathrm{m}^{2}$. However, toughness properties were reduced on increasing the loading of HNTs. Addition of 1, 3, and 5 wt $\%$ HNTs reduced the fracture toughness to $3.8,3.1$, and 3.1 MPa.m ${ }^{1 / 2}$ respectively. Similar reductions in impact toughness were observed impact toughness. 


\section{Thermal and flammability properties}

The TGA curves for vinyl-ester, eco-composites and eco-nanocomposites are shown in Figure 9 and summarized in Table 5. Here, the temperature range used was from room temperature to $800^{\circ} \mathrm{C}$. Thermal degradation, for vinyl-ester, occurred in a single stage at around $430^{\circ} \mathrm{C}$. Across all composites, the release of moisture led to slight weight loss between $60{ }^{\circ} \mathrm{C}$ to $100{ }^{\circ} \mathrm{C}$. In eco-composites, decomposition occurred in two stages with complete degradation occurring at approximately $445{ }^{\circ} \mathrm{C}$. These results also support that the eco-composites, fibre-filled polymer matrix, decompose at higher temperatures compared to pure samples. The present results are in agreement with previous studies on the thermal properties of lingo-cellulosic fibre composites. The thermal resistance of the cellulose fibres, and the ability of these natural fibres to increase char formation are responsible for the improved thermal stability. ${ }^{41}$

For eco-nanocomposites the thermal stability followed a similar trend albeit requiring a marginally higher temperature whereby eco-nanocomposites of 1,3 , and $5 \mathrm{wt} \%$ HNTs required $392^{\circ} \mathrm{C}, 394^{\circ} \mathrm{C}$ and $395^{\circ} \mathrm{C}$ respectively. In terms of weight loss, from 100 to $200^{\circ} \mathrm{C}$, eco-composites and eco-nanocomposites gave a weight loss of about $2 \%$ according to TGA analysis. At $300^{\circ} \mathrm{C}$, in eco-composites a weight loss of $11.7 \%$ was recorded. However, at the same temperature the eco-nanocomposites gave a weight loss of 11.7, 10.1, and $9.2 \%$ for loading of 1,3 and $5 \mathrm{wt} \% \mathrm{HNTs}$ respectively. Above $700^{\circ} \mathrm{C}$, the residual weight of ecocomposites was $19.7 \%$ of the original. In contrast, only $8.7 \%$ remained in the control sample. For the eco-nanocomposites with 1\%, 3\% and 5\% HNTs, the residual weight was $23.1 \%$, $23.6 \%$ and $24.7 \%$ respectively.

The improvement of interfacial adhesion between RCF and VER as a result of HNTs addition can lead to the enhancement of thermal stability. ${ }^{22}$ Nano-fillers such as HNTs are believed to provide, firstly, a thermal barrier which prevents heat transfer inside the polymer 
matrix, and secondly a mass transport barrier which during the process of degradation forms a char which hinders the escape of the volatile products. ${ }^{42,43}$ The hollow tubular structure of HNTs is also reported to be another factor that leads to enhanced thermal stability. The hollow tubular structure of HNTs enables the entrapment of degradation products inside the lumens, causing effective delay in mass transfer which leads to improved thermal stability. ${ }^{1,2}$ The presence of iron oxides, $\mathrm{Fe}_{2} \mathrm{O}_{3}$, in silicate fillers is also a possible flame retardant which serve to enhance the thermal stability of composites by trapping radicals during the process of degradation. $^{43}$

Flammability tests conducted at ambient conditions included time of burning out, ignition time, and fire velocity determinations. Pure VER samples were found to burn out and ignite faster than VER/HNT composites as indicated in Table 6. Calculations imply that fire spreads through pure VER at nearly twice the rate of $5 \mathrm{wt} \%$ VER/HNT composite, thus highlighting the favourable flammability resistance of the composites. Tthe presence of HNTs within composites provides a mechanism of insulation which protects the composites from contacting with fire. Furthermore, char formation of HNTs acts as a heat and fire-retardant.

\section{Conclusions}

Vinyl-ester eco-composites and vinyl-ester eco-nanocomposites have been fabricated and studied in terms of water uptake, thermal and mechanical properties. The addition of $5 \mathrm{wt} \%$ HNTs led to the greatest water absorption resistance compared to 1 and $3 \mathrm{wt} \%$ HNTs as evidenced by both the weight gain study and FTIR analysis. Elastic modulus and strengths properties were also found to be enhanced due to the reinforcing effect of both RCF and HNTs. In particular, HNT addition improved fibre-matrix adhesion in eco-nanocomposites and gave greater strength properties. Due to the toughness mechanism provided by cellulose fibres, the presence of cellulose fibres increased the fracture toughness of all composites. 
However, the HNT addition led to a reduction in fracture toughness due to the improvement of fibre-matrix adhesion. The HNT addition increased both the thermal stability and fireresisting properties of the eco-nanocomposites.

\section{Acknowledgments}

We are grateful to Dr. Nobuo Tezuka for providing HNTs for this study and we thank Mr. Andreas Viereckl from Mechanical Engineering at Curtin University for assistance with mechanical tests. We would also like to thank Elaine Miller and Dr. Cat Kealley for their assistance with SEM imaging and XRD data collection. Peter Chapman and Kristy Blyth from the Chemistry Department are thanked for their help in FTIR and TGA measurements. This research received no specific grant from any funding agency in the public, commercial, or not-for-profit sectors.

\section{References}

1. Ismail H, Pasbakhsh P, Fauzi MNA, and Abu Bakar A. Morphological, thermal and tensile properties of halloysite nanotubes filled ethylene propylene diene monomer (EPDM) nanocomposites. Polymer Testing 2008; 27 (7):841-850.

2. Lecouvet B, Gutierrez JG, Sclavons M and Bailly C. Structure-property relationships in polyamide 12/halloysite nanotube nanocomposites. Polymer Degradation and Stability 2011; 96 (2):226-235.

3. Handge UA, Hedicke-Höchstötter K and Altstädt V. Composites of polyamide 6 and silicate nanotubes of the mineral halloysite: Influence of molecular weight on thermal, mechanical and rheological properties. Polymer 2010; 51 (12):2690-2699.

4. Rooj S, Das A, Thakur V, Mahaling RN, Bhowmick AK and Heinrich G. Preparation and properties of natural nanocomposites based on natural rubber and naturally occurring halloysite nanotubes. Materials and Design 2010; 31 (4):2151-2156.

5. Jawaid M and Abdul Khalil HPS. Cellulosic/synthetic fibre reinforced polymer hybrid composites: A review. Carbohydrate Polymers 2011; 86 (1):1-18.

6. Arora S, Kumar M and Kumar M. Flammability and thermal degradation studies of PVA/rice husk composites. Journal of Reinforced Plastics and Composites 2012; 31 (2):85-93.

7. Osorio L, Trujillo E, Van Vuure AW and Verpoest I. Morphological aspects and mechanical properties of single bamboo fibers and flexural characterization of bamboo/ epoxy composites. Journal of Reinforced Plastics and Composites 2011; 30 (5):396408.

8. Anuar $\mathrm{H}$ and Zuraida A. Improvement in mechanical properties of reinforced thermoplastic elastomer composite with kenaf bast fibre. Composites Part B: Engineering 2011; 42 (3):462-465. 
9. Grishchuk S, Castellà N, Apostolov AA and Karger-Kocsis J. Structure and properties of vinyl ester resins modified with organophilic synthetic layered silicates bearing nonand co-reactive intercalants. Journal of Composite Materials 2012; 46:941-947.

10. $\mathrm{Ku} \mathrm{H}$, Wang $\mathrm{H}$, Pattarachaiyakoop $\mathrm{N}$ and Trada $\mathrm{M}$. A review on the tensile properties of natural fiber reinforced polymer composites. Composites Part B: Engineering 2011; 42 (4):856-873.

11. Hossain MK, Dewan MW, Hosur M and Jeelani S. Mechanical performances of surface modified jute fiber reinforced biopol nanophased green composites. Composites Part B: Engineering 2011; 42 (6):1701-1707.

12. Dhakal HN, Zhang ZY and Richardson MOW. Effect of water absorption on the mechanical properties of hemp fibre reinforced unsaturated polyester composites. Composites Science and Technology 2007; 67 (7-8):1674-1683.

13. Low IM, Somers J, Kho HS, Davies IJ and Latella BA. Fabrication and Properties of Recycled Cellulose Fibre-Reinforced Epoxy Composites. Composite Interfaces 2009; 16 (7-9):659-669.

14. Low IM, McGrath M, Lawrence D, Schmidt P, Lane J, Latella BA and Sim KS. Mechanical and fracture properties of cellulose-fibre-reinforced epoxy laminates. Composites Part A: Applied Science and Manufacturing 2007; 38 (3):963-974.

15. Joussen E, Petit S, Churchman J, Theng B, Righi D and Delvaux B. Halloysite clay minerals: a review. Clay Minerals 2005; 40 (4):383-426.

16. Deng S, Zhang J, Ye L and Wu J. Toughening epoxies with halloysite nanotubes. Polymer 2008; 49; (23):5119-5127.

17. Ladhari A, Ben Daly H, Belhadjsalah H, Cole $\mathrm{KC}$ and Denault J. Investigation of water absorption in clay-reinforced polypropylene nanocomposites. Polymer Degradation and Stability 2010; 95 (4):429-439.

18. Corobea MC, Donescu D, Grishchuk S, Castella N, Apostolov AA and Karger-Kocsis J. Organophilic layered silicate modified vinylester-urethane hybrid resins: Structure and properties. Polymers and Polymer Composites 2008; 16 (8):547-554.

19. Baiardo M, Frisoni G, Scandola M and Licciardello A. Surface chemical modification of natural cellulose fibers. Journal of Applied Polymer Science 2002; 83 (1):38-45.

20. Du M, Guo B, Lei Y, Liu M and Jia D. Carboxylated butadiene-styrene rubber/halloysite nanotube nanocomposites: Interfacial interaction and performance. Polymer 2008; 49 (22):4871-4876.

21. Jinhua W, Xiang Z, Bing Z, Yafei Z, Rui Z, Jindun L and Rongfeng C. Rapid adsorption of $\mathrm{Cr}$ (VI) on modified halloysite nanotubes. Desalination 2010; 259 (13):22-28.

22. De Rosa IM, Kenny JM, Maniruzzaman M, Moniruzzaman M, Monti M, Puglia D, Santulli C and Sarasini F. Effect of chemical treatments on the mechanical and thermal behaviour of okra (Abelmoschus esculentus) fibres. Composites Science and Technology 2011; 71 (2):246-254.

23. Sultania M, Yadaw SB, Rai JSP and Srivastava D. Laminates based on vinyl ester resin and glass fabric: A study on the thermal, mechanical and morphological characteristics. Materials Science and Engineering: A 2010; 527 (18-19):4560-4570.

24. Jebrane $M$ and Sèbe G. A new process for the esterification of wood by reaction with vinyl esters. Carbohydrate Polymers 2008; 72 (4):657-663.

25. Scott TF, Cook WD and Forsythe JS. Kinetics and network structure of thermally cured vinyl ester resins. European Polymer Journal 2002; 38 (4):705-716.

26. Lasagabáster A, Abad MJ, Barral L, Ares A and Bouza R. Application of FTIR spectroscopy to determine transport properties and water-polymer interactions in polypropylene (PP)/poly(ethylene-co-vinyl alcohol) $(\mathrm{EVOH})$ blend films: Effect of 
poly(ethylene-co-vinyl alcohol) content and water activity. Polymer 2009; 50 (13):2981-2989.

27. Qingping Guo, Cheng B, Kortschot M, Sain M, Knudson R, Deng J and Alemdar A. Performance of long Canadian natural fibers as reinforcements in polymers. Journal of Reinforced Plastics and Composites 2010; 29 (21):3197-3207.

28. Chen H, Miao M, Ding X. Influence of moisture absorption on the interfacial strength of bamboo/vinyl ester composites. Composites Part A: Applied Science and Manufacturing 2009; 40 (12):2013-2019.

29. Alhuthali A, Low IM and Dong C. Characterisation of the water absorption, mechanical and thermal properties of recycled cellulose fibre reinforced vinyl-ester econanocomposites. Composites Part B: Engineering 2012; 43 (7):2772-2781.

30. Bax B and Müssig J. Impact and tensile properties of PLA/Cordenka and PLA/flax composites. Composites Science and Technology 2008; 68 (7-8):1601-1607.

31. Kim HJ and Seo DW. Effect of water absorption fatigue on mechanical properties of sisal textile-reinforced composites. International Journal of Fatigue 2006; 28 (10):1307-1314.

32. Facca AG, Kortschot MT and Yan N. Predicting the elastic modulus of natural fibre reinforced thermoplastics. Composites Part A: Applied Science and Manufacturing 2006; 37 (10):1660-1671.

33. Zuiderduin WCJ, Westzaan C, Huétink J and Gaymans RJ. Toughening of polypropylene with calcium carbonate particles. Polymer 44 (1):261-275.

34. Stocchi A, Bernal C, Vázquez A, Biagotti J and Kenny J. A Silicone Treatment Compared to Traditional Natural Fiber Treatments: Effect on the Mechanical and Viscoelastic Properties of Jute_-Vinylester Laminates. Journal of Composite Materials 41 (16):2005-2024.

35. Shiqiang Deng and Youhong Tang. Increasing load-bearing capacity of wood-plastic composites by sandwiching natural and glass fabrics. Journal of Reinforced Plastics and Composites 29 (20):3133-3148.

36. Chandradass J, Ramesh Kumar $\mathrm{M}$ and Velmurugan R. Effect of Clay Dispersion on Mechanical, Thermal and Vibration Properties of Glass Fiber-Reinforced Vinyl Ester Composites. Journal of Reinforced Plastics and Composites 2008; 27 (15):1585-1601.

37. Avilés F, Cauich-Rodríguez JV, Rodríguez-González JA and May-Pat A. Oxidation and silanization of MWCNTs for MWCNT/vinyl ester composites. eXPRESS Polymer Letters 2011;5(9):766-776.

38. Sun L-H, Yang Z-G, Li X-H. Tensile and tribological properties of PTFE and nanoparticles modified epoxy-based polyester fabric composites. Materials Science and Engineering: A 2008; 497 (1-2):487-494.

39. Fu S-Y, Feng X-Q, Lauke B, Mai Y-W. Effects of particle size, particle/matrix interface adhesion and particle loading on mechanical properties of particulate-polymer composites. Composites Part B: Engineering 2008; 39 (6):933-961.

40. ASTM D 2734-94 (1997). Standard methods for void content of reinforced specimen plastics, american Society for Testing and Materials.

41. Curvelo AAS, de Carvalho AJF and Agnelli JAM. Thermoplastic starch-cellulosic fibers composites: preliminary results. Carbohydrate Polymers 2001; 45 (2):183-188.

42. Du M, Guo B and Jia D. Thermal stability and flame retardant effects of halloysite nanotubes on poly(propylene). European Polymer Journal 2006; 42 (6):1362-1369.

43. Rahman NA, Hassan A, Yahya R, Lafia-Araga RA and Hornsby PR. Micro-structural, thermal, and mechanical properties of injection-molded glass fiber/nanoclay/polypropylene composites. Journal of Reinforced Plastics and Composites 2012; 31 (4):269-281. 


\section{TABLES}

Table 1. XRD results of HNTs and VER/HNTs composites

\begin{tabular}{lcccccc}
\hline Specific plane & \multicolumn{2}{c}{$(001)$} & \multicolumn{2}{c}{$(020)$} & \multicolumn{2}{c}{$(002)$} \\
20/d-spacing & $2 \theta$ & $d(\mathrm{~nm})$ & $2 \theta$ & $d(\mathrm{~nm})$ & $2 \theta$ & $d(\mathrm{~nm})$ \\
\hline HNTs & 12.27 & 0.721 & 20.15 & 0.44 & 24.95 & 0.357 \\
VER/1\%HNTs & 11.87 & 0.745 & 19.85 & 0.447 & - & - \\
VER/3\%HNTs & 12.07 & 0.733 & 19.92 & 0.445 & - & - \\
VER/5\%HNTs & 12.15 & 0.728 & 19.98 & 0.444 & - & - \\
\hline
\end{tabular}

Table 2. Maximum water uptake $M_{\infty}$ and Diffusion coefficients $D$ of VER-eco and econanocomposites

\begin{tabular}{lcccc}
\hline \multicolumn{1}{c}{ Samples } & $\begin{array}{c}\text { RCF } \\
\text { Content }(\%)\end{array}$ & $\begin{array}{c}\text { HNTs } \\
\text { content }(\%)\end{array}$ & $\begin{array}{c}M_{\infty} \\
(\%)\end{array}$ & $\begin{array}{c}D \\
\left(\mathrm{~mm}^{2} / \mathrm{sec}\right)\end{array}$ \\
\hline VER & 0 & 0 & 1.29 & $2.72 \times 10^{-6}$ \\
VER/RCF & 40 & 0 & 12.83 & $2.81 \times 10^{-6}$ \\
VER/RCF/1\%HNTs & 40 & 1 & 11.44 & $2.56 \times 10^{-6}$ \\
VER/RCF/3\%HNTs & 40 & 3 & 10.28 & $2.16 \times 10^{-6}$ \\
VER/RCF/5\%HNTs & 40 & 5 & 9.58 & $2.99 \times 10^{-6}$ \\
\hline
\end{tabular}

Table 3. Elastic modulus and strength properties of pure VER, VER/RCF eco-composites and VER/RCF/HNTs eco-nanocomposites

\begin{tabular}{lcclll}
\hline Samples & $\begin{array}{c}\text { RCF } \\
\text { Content } \\
(\%)\end{array}$ & $\begin{array}{c}\text { HNTs } \\
\text { content } \\
(\%)\end{array}$ & $\begin{array}{l}\text { Elastic } \\
\text { modulus } \\
(\mathrm{GPa})\end{array}$ & $\begin{array}{l}\text { Flexural } \\
\text { strength } \\
(\mathrm{MPa})\end{array}$ & $\begin{array}{l}\text { Impact } \\
\text { strength } \\
\left(\mathrm{kJ} / \mathrm{m}^{2}\right)\end{array}$ \\
\hline VER & 0 & 0 & $2.97 \pm 0.2$ & $41.9 \pm 1.4$ & $2.6 \pm 0.2$ \\
VER/RCF & 40 & 0 & $4.82 \pm 1.1$ & $148.4 \pm 1.7$ & $15.9 \pm 1.2$ \\
VER/RCF/1\%HNTs & 40 & 1 & $5.11 \pm 1.3$ & $156.1 \pm 1.5$ & $16.81 \pm 1.5$ \\
VER/RCF/3\%HNTs & 40 & 3 & $5.75 .1 \pm 1.2$ & $161.2 \pm 1.7$ & $18.86 \pm 1.3$ \\
VER/RCF/5\%HNTs & 40 & 5 & $5.24 \pm 0.9$ & $150.2 \pm 1.3$ & $16.12 \pm 1.2$ \\
\hline
\end{tabular}

Table 4. Toughness properties of pure VER, VER/RCF eco-composites and VER/RCF/HNTs eco-nanocomposites

\begin{tabular}{lccll}
\hline Samples & $\begin{array}{c}\text { RCF } \\
\text { Content } \\
(\%)\end{array}$ & $\begin{array}{c}\text { HNTs } \\
\text { content } \\
(\%)\end{array}$ & $\begin{array}{l}\text { Fracture } \\
\text { toughness } \\
\left(\mathrm{MPa}^{1 / 2}\right)\end{array}$ & $\begin{array}{l}\text { Impact } \\
\text { toughness } \\
\left(\mathrm{kJ} / \mathrm{m}^{2}\right)\end{array}$ \\
\hline VER & 0 & 0 & $1.8 \pm 0.2$ & $1.5 \pm 0.2$ \\
VER/RCF & 40 & 0 & $4.4 \pm 0.5$ & $42.3 \pm 2.1$ \\
VER/RCF/1\%n-SiC & 40 & 1 & $3.84 \pm 0.3$ & $36.5 \pm 1.5$ \\
VER/RCF/3\%n-SiC & 40 & 3 & $3.06 \pm 0.2$ & $26.2 \pm 1.3$ \\
VER/RCF/5\%n-SiC & 40 & 5 & $3.12 \pm 0.9$ & $29.3 \pm 1.2$ \\
\hline
\end{tabular}


Table 5. TGA data of pure VER, VER/RCF eco-composites and VER/RCF/HNTs econanocomposites

\begin{tabular}{lccc}
\hline Sample & $\begin{array}{c}\text { Temperature at } \\
\text { 50\% weight loss } \\
\left({ }^{\circ} \mathrm{C}\right)\end{array}$ & $\begin{array}{c}\text { Temperature at } \\
\text { maximum weight } \\
\text { loss }\left({ }^{\circ} \mathrm{C}\right)\end{array}$ & $\begin{array}{c}\text { Residual } \\
\text { weight } \\
(\%)\end{array}$ \\
\hline VER & 418 & 430 & 8.7 \\
VER/RCF & 409 & 445 & 19.7 \\
VER/RCF/1\%HNTs & 423 & 448 & 23.1 \\
VER/RCF/3\%HNTs & 429 & 453 & 23.6 \\
VER/RCF/5\%HNTs & 431 & 460 & 24.7 \\
\hline
\end{tabular}

Table 6. Flammability properties of vinyl ester resin and its composites

\begin{tabular}{llll}
\hline Sample & $\begin{array}{l}\text { Burning out rate } \\
(\mathrm{g} / \mathrm{min})\end{array}$ & $\begin{array}{l}\text { Ignition time } \\
(\mathrm{s})\end{array}$ & $\begin{array}{l}\text { fire velocity } \\
(\mathrm{mm} / \mathrm{min})\end{array}$ \\
\hline VER & $0.67 \pm 0.06$ & $10.8 \pm 1.6$ & $31.5 \pm 1.7$ \\
VER/RCF & $0.54 \pm 0.03$ & $17.2 \pm 1.5$ & $25.7 \pm 1.6$ \\
VER/RCF/1\%HNTs & $0.49 \pm 0.02$ & $18.7 \pm 1.4$ & $23.2 \pm 1.2$ \\
VER/RCF/3\%HNTs & $0.46 \pm 0.04$ & $22.8 \pm 1.2$ & $19.1 \pm 1.8$ \\
VER/RCF/5\%HNTs & $0.41 \pm 0.05$ & $25.4 \pm 1.8$ & $17.5 \pm 1.4$ \\
\hline
\end{tabular}




\section{FIGURE CAPTIONS}

Figure 1. XRD pattern of pure HNTs and VER/HNT composites.

Figure 2. (a) SEM micrograph of HNT particles and (b) TEM micrograph of HNT particles.

Figure 3. Dispersion of HNTs particles within composites (a) $1 \mathrm{wt} \%$ of HNTs, (b) $3 \mathrm{wt} \%$ of HNTs (c) $5 \mathrm{wt} \%$ of HNTs.

Figure 4. Water absorption behaviour of VER, VER/RCF, VER/RCF/1\%HNTs, VER/RCF/3HNTs and VER/RCF/5\%HNTs.

Figure 5. FTIR Dry and Wet spectrums of (a) VER/RCF eco- composites (b) VER/RCF/1\%HNT eco-nanocomposites (c) VER/RCF/3\%HNT eco-nanocomposites and (d) VER/RCF/5\%HNT eco-nanocomposites.

Figure 6. Comparison between FTIR spectrums peaks of water content of eco-composites and eco-nanocomposites.

Figure 7. SEM images showing the fracture surfaces of (a) eco-composite, (b) econanocomposite with $1 \mathrm{wt} \%$ HNT loading, (c) eco-nanocomposite with $3 \mathrm{wt} \%$ HNTs loading (d) eco-nanocomposite with $5 \mathrm{wt} \%$ HNTs loading.

Figure 8. SEM images showing the fracture surfaces of eco-nanocomposites contain (a) 1 wt $\%$ HNTs (b) $3 \mathrm{wt} \%$ HNTs and (c) $5 \mathrm{wt} \%$ HNTs with existing of voids.

Figure 9. TGA curves of VER, VER/RCF, VER/RCF/1\%HNTs, VER/RCF/3HNTs and VER/RCF/5\%HNTs. 